INFORMES

\title{
Las cláusulas relativas al uso y tratamiento de datos personales y el artículo 16 letra g) de la Ley 19.496 sobre Protección de los Derechos de los Consumidores
}

\author{
Contractual terms on the use and processing of personal data and article $16 \mathrm{~g}$ ) \\ of the Chilean Protection Consumer Act (Law 19,496)
}

\author{
Rodrigo Momberg Uribe \\ Pontificia Universidad Católica de Valparaíso, Chile
}

María Elisa Morales Ortiz (iD)

Universidad de la Frontera, Chile

RESUMEN A partir de dos fallos de la Corte Suprema, el artículo analiza los supuestos para la declarar como abusiva una cláusula sobre uso y tratamiento de datos personales. El estudio se efectúa desde la perspectiva del derecho del consumidor, en particular, a partir de los dispuesto en el artículo 16 letra g) de la Ley 19.496. Se concluye que la infracción a la buena fe y el desequilibrio importante a que se refiere dicha norma se configuran por la pretensión del proveedor, mediante una autorización amplia y poco definida, de recolectar, usar y tratar datos personales del usuario más allá de los necesarios para la celebración o ejecución del contrato, o para fines completamente ajenos a él.

PALABRAS CLAVE Datos personales, cláusulas abusivas, términos y condiciones.

ABSTRACT From two decisions of the Supreme Court, the paper analyses the requirements to declare as unfair a term for the use and processing of personal data. The study is made from a consumer law perspective, in particular, article 16 letter g) of the Law 19,496. It concludes that the contravention of good faith and the significant imbalance required by that provision are met when the term authorizes the provider to collect, use and process personal data beyond those required for the execution or performance of the contract, or for purposes far removed from the contractual relationship.

KEYWORDS Personal data, unfair terms, terms and conditions. 


\section{Introducción}

Hasta hace poco tiempo, la protección de datos personales y el derecho del consumidor constituían compartimentos separados, cada uno con su propio estatuto legal. La protección de datos personales se relaciona históricamente con el resguardo de derechos fundamentales como la honra y la vida privada. En cambio, el derecho del consumidor pretende proteger a dicho sujeto frente a los abusos de los proveedores en una economía de mercado.

La falta de comunicación formal entre ambas áreas es patente en nuestro ordenamiento. La protección de datos personales se regula en la Ley 19.628, promulgada en 1999, y la protección del consumidor se contiene en la Ley 19.496, del año 1997. La Ley 19.628 no hace referencia al consumidor. La ley 19.496 solo menciona los datos personales en su artículo 37 , en materia de cobranza extrajudicial de créditos que se otorgan directamente al consumidor. ${ }^{1}$

Sin embargo, el desarrollo de la economía en línea ha alterado profundamente esta relación. Los términos y condiciones con que los proveedores pretenden regir la contratación de bienes y servicios que ofrecen en línea incluyen sin falta cláusulas sobre uso y tratamiento de datos personales. El objeto de tales cláusulas va mucho más allá de la legítima necesidad de individualizar al contratante: la recolección de los datos de los usuarios se ha transformado en un negocio en extremo lucrativo, mediante su tratamiento y comercialización, en lo que se conoce como el modelo de negocios del big data. ${ }^{2}$ Ello es evidente en los servicios que se prestan de manera al parecer gratuita para el usuario, en los cuales la contraprestación está constituida justamente por los datos que estos entregan a los proveedores (Momberg Uribe, 2019). La expansión del denominado internet de las cosas ha incrementado de manera exponencial la cantidad de datos a los que los proveedores pueden acceder y, por tanto, utilizar en beneficio de su propio negocio o para su comercialización a terceros.

El presente trabajo pretende analizar un aspecto en el que el derecho sobre datos personales y el derecho del consumidor han comenzado a superponerse: la determinación de si una cláusula sobre uso y tratamiento de datos personales - que formal-

1. No es propósito de este trabajo analizar los problemas relacionados con la aplicación de la Ley 19.496 y la Ley 19.628. Para ello, véase Momberg Uribe (2017).

2. Se trata de «un conjunto de información tan voluminoso y complejo que escapa al concepto de procesamiento de datos tradicional [...] La idea detrás es simple: los datos son información y ello proporciona una ventaja competitiva que se transforma en ingresos. Entre más datos, más ganancias. Una parte importante de esta información se refiere a las preferencias, los hábitos, las características y el comportamiento de personas identificadas o identificables. Así, a través del análisis computarizado de datos, las compañías generan perfiles de usuarios que actualmente se extienden a cada aspecto y fase de la vida individual y social de las personas. Esta información tiene una gran importancia económica, ya que se utiliza para crear valor agregado e innovación en la economía digital actual» (Frigeiro, 2018: 51). 
mente cumpla con los requisitos que la normativa sobre dicha materia exige- pueda ser considerada como abusiva si se examina desde la perspectiva de la legislación de protección al consumidor.

El objetivo anterior implica partir de dos supuestos: que el usuario o consumidor ha prestado su consentimiento al contrato respectivo y a la cláusula en particular; y que se ha cumplido con el deber de transparencia que permite que dicho consentimiento pueda considerarse como otorgado de manera válida. ${ }^{3}$ Se trata entonces de efectuar un análisis sustantivo y no formal de las referidas cláusulas.

Por ello, el trabajo se estructura a partir de dos casos en los que se ha discutido este asunto. Primero, una reciente sentencia de la Corte Suprema, que se pronuncia respecto de lo abusivo de una cláusula de este tipo, contenida en contrato de cuenta corriente celebrado de manera presencial (el caso BBVA). Segundo, una sentencia de la Corte Suprema relativa a términos y condiciones en línea, que ya ha sido analizada por la doctrina nacional, pero que ahora se examina desde la perspectiva del artículo 16 letra g) (el caso Ticketmaster). En términos sustantivos, en ambos casos las cláusulas sobre uso y tratamiento de datos personales son similares. El análisis conjunto permite que las conclusiones de este estudio sean aplicables tanto a contratos celebrados entre presentes como a aquéllos celebrados por medios remotos.

\section{Los casos}

\section{Sernac con BBVA}

El caso refiere a una acción para la protección del interés colectivo de los consumidores, deducida por el Servicio Nacional del Consumidor (Sernac) en contra del Banco BBVA, por la cual se demandó - entre otras cuestiones- la nulidad de una serie de cláusulas contenidas en contratos asociados a planes de cuentas corrientes de los clientes de dicho banco.

Una de las cláusulas cuya nulidad se alegó, por contravenir lo dispuesto en el artículo 16 letra g) de la Ley 19.496, fue la denominada «Tratamiento y transmisión de datos»:

El banco podrá entregar a su matriz, filiales, sociedades de apoyo al giro y relacionadas, los antecedentes legales, financieros y laborales del que tenga en su poder, al objeto de que éstas puedan ofrecerle sus productos y servicios. Asimismo, el banco podrá informar las obligaciones impagas del cliente al Boletín Comercial y a Sinacofi. Finalmente, el Banco podrá entregar información del cliente y sus operaciones a terceros para su procesamiento, en Chile o el exterior.

Los tribunales de la instancia y la Corte Suprema estimaron que dicha cláusula

3. Sobre estos temas, véase De la Maza y Momberg Uribe (2018). 
era nula solo en aquella parte en que se autorizaba al banco a entregar la información del cliente a terceros no relacionados. Conviene reproducir los argumentos utilizados por los tribunales para llegar a esta conclusión.

En primera instancia, el tribunal indicó:

Que no se divisa que esta cláusula atente en contra de la buena fe y que cause un desequilibrio en perjuicio del cliente, en la medida que la información se comparta entre los distintos departamentos de la entidad bancaria o personas jurídicas relacionadas a ella, por lo que no se declarará abusiva. Se trata de facultades informativas, que no necesariamente implican una indefensión para el consumidor. Lo mismo cabe concluir respecto de las obligaciones impagas comunicadas al Boletín Comercial y a Sinacofi.

Que no sucede lo mismo con la entrega de información a terceros, pactada en términos abiertos, no vislumbrándose su justificación y propósito, razón por la que se le estima abusiva. ${ }^{4}$

La Corte de Apelaciones coincidió con el razonamiento del juez inferior, señalando que:

La cláusula «Tratamiento y transmisión de datos», declarada nula solo en parte, en aquélla no alcanzada por la declaración de nulidad también se ajusta a las exigencia de la ley, puesto que la entrega de datos del cliente que el banco tenga en su poder y aunque no hayan sido proporcionados directamente por éste - que es la hipótesis en que se sitúa el apelante-, en tanto sea a su matriz, filiales, sociedades de apoyo al giro y relacionadas (que debe entenderse no son terceros, por lo que estatuía la parte final que se excluyó por el fallo de primer grado), no importa la entrega de información con quien el consumidor no ha contratado, que es aquello que resulta efectivamente reprochable. ${ }^{5}$

Por último, la Corte Suprema rechazó la casación alegada en este aspecto por ambas partes, determinando:

Trigésimo sexto: Que sobre tal asunto ha de señalarse que no puede ser atentatorio contra la buena fe ni lesiona el interés del cliente la circunstancia de que la información de que dispone el banco sobre el mismo como sujeto de crédito circule o se comparta entre las diversas unidades de la institución bancaria o personas relacionadas a ella, lo que incluso podrá beneficiarle.

No parece justificable, en cambio, la atribución que se confiere al banco para entregar informaciones a toda clase de terceros - con quienes el consumidor no ha contratado- y que resulta amplia o excesiva, considerando la finalidad indicada como justificación por parte del demandado — abrir al cliente la posibilidad de otros

4. Sentencia del 30..$^{\circ}$ Juzgado Civil de Santiago, rol C-19203-2012, 23 de marzo de 2016.

5. Sentencia de la Corte de Apelaciones de Santiago, rol 5310-2016, 3 de octubre de 2016. 
productos y servicios - sin que aparezca clara la conveniencia de entregar esa información al no haber tampoco seguridad sobre el tratamiento que se dará a ella, sin perjuicio de la que corresponda entregar al Boletín Comercial y al Sistema Nacional de Comunicaciones Financieras.

Por lo tanto, no se aprecia que en el aspecto que apunta el demandante la cláusula sea abusiva, pues no se advierte que atente contra la buena fe ni provoque desequilibrios en perjuicio del cliente, por tratarse, como lo expresa el fallo, de actos comunicacionales que no colocan al consumidor en posición de indefensión, en la medida que se trate de una información interna que cubra las necesidades de oferta de servicios de diversos departamentos de la misma institución bancaria o personas relacionadas con ella. En cambio, sí parece abusivo que el banco pueda entregar información de su cliente a otros terceros, ámbito en el cual ya no se vislumbra la justificación y propósito invocado por dicha parte.

La otra matización que formula el demandante en cuanto a la referencia que la cláusula hace a la trasmisión de datos del cliente «que el banco tenga en su poder», y que entiende como aquéllos no necesariamente entregados por el deudor, no refleja una clara demostración de irregularidad o abuso, a menos que en la situación particular y de modo expreso el consumidor haya prohibido la trasmisión o divulgación de cierta información, operando en tal evento la normativa de protección de datos reservados.

Consiguientemente, la sentencia impugnada no incurre en los errores de derecho que denuncian ambos impugnantes en los aspectos que cada cual censura. ${ }^{6}$

Tal como lo hemos planteado en la introducción, los tribunales de la instancia y la Corte Suprema parten del supuesto de que el consumidor ha en efecto prestado su consentimiento al contrato de que se trata y, por tanto, a la cláusula impugnada. No es eso entonces lo que se cuestiona.

El cuestionamiento se refiere a las facultades del banco respecto de la información que el consumidor le provee. Los fallos no objetan que el proveedor pueda utilizar la información legal, financiera y laboral del cliente para efectos de ofrecerle productos y servicios, incluso por medio de entidades relacionadas. Lo que a juicio de los tribunales parece desproporcionado es que esa información pueda ser entregada a terceros ajenos al proveedor (el banco), sin una explicitación del objeto o propósito de dicha entrega.

Tanto los tribunales de la instancia como la Corte Suprema estiman que no existe nada abusivo ni ilegítimo en que el banco proveedor utilice la información que el cliente le ha proporcionado, para el uso señalado en la cláusula, esto es, «ofrecerle sus productos o servicios», lo que para la Corte Suprema «incluso podrá beneficiarle».

Sin embargo, la entrega de información a terceros no relacionados y sin un propó-

6. Sentencia de la Corte Suprema, rol 100.759-2016, 29 de noviembre de 2018. 
sito definido es estimada como «amplia y excesiva», y por ello abusiva, ya que excede la justificación o propósito legítimo del uso de los datos personales del consumidor, que éste - presumiblemente- ha autorizado.

\section{Sernac con Ticketmaster}

Analizado el razonamiento de la Corte Suprema en $B B V A$, parece conveniente referirse a otro caso similar fallado por el mismo tribunal. Se trata de la sentencia recaída en Sernac con Ticketmaster. ${ }^{7}$ En dicho caso, también se impugnó la validez de una cláusula sobre uso y tratamiento de datos personales, denominada «Política de privacidad de Ticketmaster», que se reclama comete infracción del artículo 16 letra g). La cláusula era del siguiente tenor:

Ticketmaster podrá revelar la información proporcionada por sus usuarios a terceros, incluyendo patrocinadores, publicistas y/o socios comerciales. Ticketmaster también recolectará información que es derivada de los gustos, preferencias y en general de la utilización que hacen los usuarios de los servicios. Dicha información derivada, al igual que la información personal que los usuarios proporcionen, podrá ser utilizada para diversos objetivos comerciales, como lo es el proporcionar datos estadísticos (por ejemplo: $50 \%$ de nuestros usuarios son mujeres) a anunciantes potenciales, enviar publicidad a los usuarios de acuerdo a sus intereses específicos, conducir investigaciones de mercadeo, y otras actividades o promociones que Ticketmaster considere apropiadas. Ticketmaster también podrá revelar información cuando por mandato de ley y/o de autoridad competente le fuere requerido o por considerar de buena fe que dicha revelación es necesaria para: i) cumplir con procesos legales; ii) cumplir con el convenio del usuario; iii) responder reclamaciones que involucren cualquier contenido que menoscabe derechos de terceros o; iv) proteger los derechos, la propiedad, o la seguridad de Ticketmaster, sus usuarios y el público en general.

Si bien esta cláusula había sido considerada válida en primera y segunda instancia, la Corte Suprema acogió el recurso de casación interpuesto por el Sernac, y la invalidó -salvo en su última parte- por infringir el tantas veces mencionado artículo 16 letra g). Lo fundamental del razonamiento de la Corte está contenido en el considerando undécimo del fallo, el cual conviene reproducir en toda su extensión:

Esta cláusula contiene diversas autorizaciones a Ticketmaster. No son sin embargo autorizaciones que el usuario dé positiva y especialmente. Tampoco son autorizaciones supletorias que el usuario pueda denegar si así lo desea. Son autorizaciones que se entienden concedidas por el consumidor por el solo hecho de usar el sitio. Esta característica resultará determinante para establecer el carácter abusivo de buena parte de estas autorizaciones.

7. Sentencia de la Corte Suprema, rol 1533-2015, 7 de julio de 2016. 
La primera autorización permite a Ticketmaster «revelar la información proporcionada por sus usuarios a terceros, incluyendo patrocinadores, publicistas y/o socios comerciales». Esta autorización para revelar información supone los dos procesos previos de obtención y almacenamiento de la información. La obtención de cierta información es ciertamente necesaria para generar las transacciones comerciales de venta de entradas. El operador del sitio necesita, al menos, la identidad del consumidor, la información relativa al medio de pago utilizado, e información para el despacho físico o virtual del comprobante de la transacción. Con tal objeto, el operador requerirá cierta información a objeto de proceder a la transacción. La cláusula no limita sin embargo la información requerida a aquélla que sea estrictamente necesaria para cursar la transacción. Por el contrario, la segunda autorización se refiere precisamente a la recopilación de información por el operador, que se extiende a la «derivada de los gustos, preferencias y en general de la utilización que hacen los usuarios de los servicios». Pero lo cierto es que la cláusula ni siquiera limita a estos últimos parámetros la información que pueda requerir del consumidor. En tal sentido, la referencia a la información "proporcionada» por los usuarios es engañosa, pues es el propio operador del sitio quien determina qué información solicitar para procesar la transacción.

$\mathrm{Al}$ resolver el presente recurso, esta Corte no ha sido llamada a calificar si esta ilimitada facultad para requerir información es o no contraria a la buena fe. Ella constituye sin embargo un antecedente de importancia para evaluar la conformidad de la autorización a revelar información que ahora se analiza: en la medida en que la información recopilada no aparece delimitada, la autorización a revelar información a terceros aparece asimismo ilimitada.

Por su parte, el inciso primero artículo 4 de la Ley 19.628 sobre protección de datos de carácter personal dispone: «El tratamiento de los datos personales solo puede efectuarse cuando esta ley u otras disposiciones legales lo autoricen o el titular consienta expresamente en ello». La letra o) del artículo 2 de la misma ley, al definir lo que se entiende por tratamiento de datos, comprende «cualquier operación o complejo de operaciones o procedimientos técnicos, de carácter automatizado o no, que permitan $[\ldots]$ comunicar, ceder, transferir $[\ldots]$ datos de carácter personal».

En consecuencia, la revelación de datos personales a terceros, salvo que lo autorice la ley o que el titular de los datos consienta en ello, es ilegal. El derecho protegido por estas disposiciones es la protección de la vida privada, explícitamente garantizado por el artículo 19 número 4 de la Constitución Política. Resulta contraria a la buena fe, y en consecuencia abusiva, la obtención del consentimiento del titular de los datos mediante una condición general de contratación incluida en una transacción cuyo objeto principal es la entrada a un espectáculo. En el contexto de semejante transacción comercial, tal renuncia a la privacidad de los datos personales solo es válida si es otorgada en forma explícita y específica. ${ }^{8}$

8. Los considerandos 12 y 13 se refieren a otras partes de la cláusula, también estimadas abusivas por la Corte, y reiteran en lo esencial los argumentos ya expuestos en el citado considerando 11. 
Este fallo ya se ha analizado en otros trabajos desde la perspectiva de la existencia o no de consentimiento - y por tanto de contrato- por parte del usuario (De la Maza y Momberg Uribe, 2017). Como se ha dicho en tales trabajos, un examen de esa naturaleza debía llevar necesariamente a la conclusión de que no había existido consentimiento por parte del usuario, por lo que analizar el supuesto abuso de la cláusula parecía superfluo. Sin embargo, interesa ahora examinar el razonamiento de la Corte en cuanto al carácter abusivo de la cláusula.

Una primera mirada podría llevar a estimar que la Corte vincula lo abusivo de la cláusula - que a su vez se limita a la contravención a la buena fe, sin hacer referencia al desequilibrio importante en las prestaciones- al incumplimiento de los requisitos para la obtención del consentimiento según lo establecido en el artículo 4 de la Ley 19.628.

Por cierto, en estricto rigor, se trata de dos cuestiones distintas: si falta el consentimiento requerido por el citado artículo 4 , la recolección y uso de los datos personales de los usuarios carecerá de base legal y será, por ese motivo, ilícita. No es necesario recurrir a las normas sobre cláusulas abusivas. Simplemente, no habrá contrato, o al menos, no habrá consentimiento (autorización) respecto del uso y tratamiento de los datos personales. 9

Sin embargo, una lectura más detenida del fallo permite concluir que lo en verdad abusivo para la Corte es que la autorización que el consumidor se ve obligado a prestar para contratar el servicio es en exceso amplia, tanto en lo relativo a los datos que se permite recolectar como al uso que el proveedor puede dar a esos datos, si se toma en cuenta que el objeto de la prestación principal es un servicio que no requiere de manera natural la recolección ni uso de tales datos.

Planteados los casos, y su resolución por los tribunales, en el apartado siguiente se analizará la cuestión desde la perspectiva del artículo 16 letra g) de la Ley de Protección al Consumidor. Ello implica determinar cuándo una cláusula de esta especie puede considerarse contraria a la buena fe, lo que causaría un desequilibrio importante en perjuicio del consumidor.

\section{Ley de Protección del Consumidor}

Conviene comenzar recordando el texto del artículo 16 letra g) de la Ley de Protección del Consumidor, el cual indica:

No producirán efecto alguno en los contratos de adhesión las cláusulas o estipulaciones que: [...] g) En contra de las exigencias de la buena fe, atendiendo para estos

9. «En nuestro país, el principio de licitud para el tratamiento de datos personales se estructura bajo un sistema binario de consentimiento o autorización legal» (Contreras Vásquez y Trigo Kramcsák, 2019: 102), por lo tanto, ésas son las dos únicas fuentes que dan legitimidad al tratamiento de datos personales. 
efectos a parámetros objetivos, causen en perjuicio del consumidor, un desequilibrio importante en los derechos y obligaciones que para las partes se deriven del contrato. Para ello se atenderá a la finalidad del contrato y a las disposiciones especiales o generales que lo rigen. Se presumirá que dichas cláusulas se encuentran ajustadas a exigencias de la buena fe, si los contratos a que pertenecen han sido revisados y autorizados por un órgano administrativo en ejecución de sus facultades legales.

Tomando en consideración las cláusulas y extractos de las sentencias transcritos en los apartados anteriores, para efectos de su análisis a partir del artículo 16 letra g), la pregunta que surge es: ¿en qué términos resulta abusiva aquella cláusula que autoriza el tratamiento de datos personales? o, más en concreto, ¿es una concesión amplia al proveedor, en materia de recolección, uso y tratamiento de datos personales, motivo para declarar abusiva una cláusula de dicha especie?

La respuesta implica abordar dos aspectos: i) precisar los conceptos de buena fe y de desequilibrio importante como elementos del supuesto normativo, y, ii) distinguir entre contratos a título oneroso, es decir, aquéllos en que el usuario paga por el bien o servicio y, contratos a título gratuito, o como se explicará, aparentemente a título gratuito, es decir, aquéllos en que no existe contraprestación dineraria por parte del usuario, limitándose éste a conceder al proveedor el acceso y uso a sus datos personales a cambio de la prestación de los servicios.

\section{Buena fe y desequilibrio importante como elementos del supuesto normativo}

Antes de analizar cada uno de estos conceptos en forma separada a la luz de los casos seleccionados, conviene sintetizar la discusión que se ha generado en nuestro medio sobre la exigencia conjunta de ambos elementos.

Una doctrina (De la Maza, 2012: 137), al analizar la norma citada, señala que, según su tenor, para determinar el carácter abusivo de una cláusula se debe considerar en primer lugar la vulneración de las exigencias de la buena fe y, en seguida, el desequilibrio importante, como un efecto de lo primero, por lo que es ineludible la exigencia conjunta de ambos requisitos pues, a su juicio, es posible que una cláusula respete las exigencias de la buena fe $\mathrm{y}$, sin embargo, produzca un desequilibrio importante $-\mathrm{y}$ viceversa-. Esta interdependencia de ambos elementos se expresa en dos ideas: primero, que la existencia de un desequilibrio importante pueda constituir la base de una presunción de mala fe por parte del predisponente (Polo, 1990: 106); y, segundo, que «la contravención a las exigencias de la buena fe debe traducirse en un desequilibrio importante en perjuicio del consumidor, en los derechos y obligaciones que se deriven del contrato para las partes» (De la Maza, 2012: 143).

Otra doctrina (Momberg Uribe, 2013b: 18) recoge la crítica que los instrumentos europeos han generado a partir de la exigencia conjunta de ambos elementos. Esta doctrina sostiene la idea según la cual una cláusula que cause una ventaja injustifica- 
da y significativa a favor del proveedor es siempre incompatible con la buena fe contractual. Se agrega que la exigencia conjunta de ambos elementos presenta el inconveniente del carácter abstracto del concepto mismo de buena fe, que puede generar interpretaciones diversas en cuanto a su significado en el caso concreto.

Una primera revisión de la jurisprudencia nacional - hasta el año 2013 - revela una tendencia a examinar el contenido del contrato en relación con el equilibrio de las contraprestaciones entendiendo, al parecer, que es la desproporción significativa en las contraprestaciones la que configura una contravención a la buena fe, y no al revés (Momberg Uribe y Pizarro, 2013). De ello, se concluye que el elemento esencial, utilizado por los tribunales para la determinación de lo abusivo, es la existencia de una desproporción significativa entre las contraprestaciones, la cual acarrearía la contravención a la buena fe por parte del predisponente. Abona esa conclusión la idea según la cual la sola circunstancia que el proveedor establezca ventajas excesivas e injustificadas en detrimento de la parte débil, debería ser suficiente demostración de abuso como para ser sancionado por el ordenamiento jurídico.

La tendencia jurisprudencial señalada parece haberse mantenido a lo largo del tiempo (Morales, 2019: 202). En este sentido, se pueden citar, entre otras, la sentencia de la Corte de Apelaciones de Santiago del 28 de enero de 2014, ${ }^{10}$ que en su considerando quinto señala: «Como ya se dijo, lo que en esencia le otorga el carácter de abusiva a la cláusula en un contrato de adhesión es el desequilibrio en los derechos y obligaciones que para las partes se derivan del contrato».

Otro ejemplo es el fallo de la Corte de Apelaciones de Santiago del 8 de septiembre de $2015,{ }^{11}$ que en su considerando tercero sostiene:

Que, en relación al primer aspecto de la apelación de la demandada, esto es si la cláusula cuarta debe considerarse o no abusiva, cabe agregar que [...] debe considerarse abusiva porque ocasiona un claro desequilibrio entre los derechos del consumidor frente a los del proveedor, desde el momento que la demandada está vendiendo un servicio que lleva implícitas esas alternativas desmedidas.

En el mismo sentido, la Corte de Apelaciones de Antofagasta, en el considerando octavo de la sentencia del 16 de octubre de $2017,{ }^{12}$ sostuvo:

El consumidor paga un pasaje que comprende dos tramos e impedirle tomar alguno de los tramos si por alguna razón no toma el tramo inicial, constituye, de cara a la contraprestación a favor de la aerolínea, un grave desequilibrio y se traduce en una cláusula abusiva evidente.

10. Sentencia de la Corte de Apelaciones de Santiago, rol 887-2014, 28 de enero de 2015.

11. Sentencia de la Corte de Apelaciones de Santiago, rol 663-2015, 8 de septiembre de 2015.

12. Sentencia de la Corte de Apelaciones de Antofagasta, rol 109-2017, 16 de octubre de 2017. 
Sin embargo, hay que reconocer que el asunto de la exigencia conjunta de ambos elementos (buena fe y desequilibrio) o solo uno de ellos - y cuál de ellos- no se encuentra zanjado. En un fallo reciente, la Corte Suprema ${ }^{13}$ se ha decantado por la exigencia conjunta de ambos requisitos para entender la configuración de esta causal de abuso, señalando que

tal como se ha venido analizando, el criterio determinante para calificar una cláusula de abusiva consiste en dilucidar si [...] el contenido de la misma vulnera la buena fe y si en ella se advierte una desproporción entre los derechos de las partes, ya que solo en la medida que concurran los elementos antes reseñados será posible considerarla como abusiva.

\section{La buena fe}

Como se sabe, el concepto de la buena fe ha presentado bastantes dificultades de precisión, debido a la flexibilidad y amplitud propia de un principio general del derecho. Antes de intentar delimitar este concepto, se debe tener en cuenta que, en el ámbito del control de cláusulas abusivas, la buena fe es considerada en su vertiente objetiva, como textualmente lo señala el artículo 16 letra g). En este sentido, es un concepto «ético-social y jurídico» al servicio del juez para sancionar una conducta como ajustada o no a derecho o, en otras palabras, un patrón de conducta que obliga a comportarse con «corrección, lealtad, honradez y rectitud» (Boetsch, 2015: 41).

En el campo más específico del examen de abuso, la buena fe objetiva se ha relacionado con la razonabilidad. Así, por ejemplo, el Tribunal de Justicia de la Unión Europea, en el caso $A z i z{ }^{14}$ resume bien el examen que el juez debe hacer para evaluar la buena o mala fe de un proveedor, al indicar que el tribunal deberá determinar si el proveedor "podía estimar razonablemente que, tratando de una manera leal y equitativa con el consumidor, éste aceptaría una cláusula de ese tipo en el marco de una negociación individual». En un sentido similar, respecto de la redacción de las cláusulas, se ha sugerido que el proveedor debe considerar los intereses del consumidor, y por tanto abstenerse de defraudar sus expectativas razonables. Así, la buena fe en este contexto es un límite para el proveedor, quien no puede defraudar las expectativas del adherente alterando de manera no razonable el equilibrio entre las prestaciones (Tapia y Valdivia, 1999: 86).

Darle este alcance a la buena fe permite relacionar el asunto con las denominadas «cláusulas sorpresivas», que son aquéllas que «el adherente no pudo razonablemente

13. Sentencia de la Corte Suprema, rol 79123-2016, 7 de marzo de 2018.

14. Sentencia del Tribunal de Justicia de la Unión Europea, ECLI:EU:C:2013:164, de 14 de marzo de 2013. 
esperar» (Díez-Picazo, 1993: 351) o cláusulas que sorprenden por estar insertas en un contexto donde no debían estarlo de manera natural, como es en efecto el caso de las cláusulas objeto de este trabajo. Así, serían contrarias a la buena fe objetiva las cláusulas en que el consumidor adherente autoriza al proveedor para revelar sus datos personales a terceros, por alejarse esta prestación del objeto principal del contrato, por lo que resulta de esta manera sorpresiva para el consumidor, quien no podía esperar de manera razonable que al contratar un servicio financiero o al comprar la entrada para un evento, estuviere dando aquella autorización.

Por otro lado, la infracción de la buena fe objetiva como elemento de abuso permite al intérprete concretar la transgresión del principio desde su faz negativa o por oposición, de acuerdo con la teoría del excluder analysis, según la cual en sede contractual la buena fe funciona excluyendo una amplia gama de formas de mala fe (Summers, 1968: 206-208). Desde esta perspectiva, la función de buena fe objetiva sería proscribir «conductas deshonestas, oportunistas o abusivas» (Eyzaguirre y Rodríguez, 2013: 144). El propio tenor del artículo 16 letra g) favorece el empleo de esta técnica: «En contra de las exigencias de la buena fe, atendiendo para estos efectos a parámetros objetivos».

De acuerdo con lo anterior, es contrario a la buena fe insertar ciertas cláusulas consideradas abusivas en el contrato que rige la relación de consumo. Toca al intérprete precisar aquello que constituye esa conducta «abusiva».

Conviene, para ilustrar estas ideas, retornar a lo resuelto por la Corte Suprema en el caso Ticketmaster:

Resulta contraria a la buena fe, y en consecuencia abusiva, la obtención del consentimiento del titular de los datos mediante una condición general de contratación incluida en una transacción cuyo objeto principal es la entrada a un espectáculo. ${ }^{15}$

Que la cláusula «Política de privacidad de Ticketmaster», al autorizar a recolectar «información que es derivada de los gustos, preferencias y en general de la utilización que hacen los usuarios de los servicios», también contraviene la buena fe en los términos proscritos por el artículo 16 letra g) de la ley de protección de los derechos del consumidor [...]. Se trata por otra parte de información que excede de la necesaria para concluir las transacciones de compraventa de entradas, de manera que su recolección requiere o autorización legal o expreso consentimiento del titular de los datos. Por razones idénticas a las señaladas en el considerando precedente, resulta abusiva y nula esta cláusula en cuanto por ella se busca obtener tal consentimiento en forma atada a una operación comercial con un objeto diferenciado. ${ }^{16}$

De lo anterior es posible concluir que, tratándose de cláusulas sobre tratamiento de datos, según la doctrina de la Corte Suprema en el caso citado, es contraria a la

15. Sentencia de la Corte Suprema, rol 1533-2015, 7 de julio de 2016, considerando 11, parte final. 16. Sentencia de la Corte Suprema, rol 1533-2015, 7 de julio de 2016, considerando 12. 
buena fe objetiva la conducta que pretende obtener el consentimiento del titular de los datos personales en forma atada en el contexto de un contrato que tiene un objeto principal diverso. En definitiva, retomando las ideas planteadas en los párrafos anteriores, se trata de una cláusula que presumiblemente el consumidor no habría aceptado en un contrato negociado de forma libre; y que tampoco podía de manera razonable esperar que se incluyera, al tomar en cuenta el objeto del contrato.

Por último, vale la pena referirse a la interpretación que - en uno de los casos analizados- se le dio a la presunción de buena fe que el artículo en comento contiene para los contratos que han sido revisados y autorizados por un órgano administrativo en ejecución de sus facultades legales.

En el caso Sernac con BBVA, la parte demandada alegó la presunción de buena fe en sus contratos de adhesión por encontrarse revisados y autorizados por la Superintendencia de Bancos e Instituciones Financieras, y agregó que además las mismas cláusulas fueron revisadas y aceptadas por el Sernac en un proceso de negociación en el año 2010.

A este respecto, el tribunal de alzada entendió que al tratarse de una presunción simplemente legal, admite prueba en contrario y que, si en efecto las cláusulas han sido sometidas al conocimiento y autorización de un órgano administrativo, dicha circunstancia provee al juez de una base que no lo inhabilita para declarar su carácter abusivo si tal circunstancia es la que resulta del mérito del proceso. ${ }^{17}$ Por su parte, sobre la misma cuestión, la Corte Suprema agrega que la presunción a la que se refiere el artículo 16 letra g) no implica la intangibilidad o imposibilidad de revisión del contrato por la justicia ordinaria, pues la normativa legal ha otorgado amplias competencias a los tribunales de justicia para conocer de cláusulas contenidas en contratos de adhesión. ${ }^{18}$

\footnotetext{
17. «Sin embargo, es claro que cuando el legislador ha consagrado una regla como la de la última parte del inciso primero de la letra g) del artículo 16 ha querido significar que si el contrato ha sido revisado y autorizado por un órgano administrativo en ejercicio de sus atribuciones legales, el juez que conoce del proceso por eventual infracción a la Ley de Protección de los Derechos de los Consumidores debe partir de la base que las cláusulas de la convención se ajustan a las exigencias de la buena fe, pero si su convencimiento, a la luz de los preceptos y principios de ese cuerpo normativo - que por cierto no son aquéllos cuyo cumplimiento revisa el órgano administrativo- lo conducen a la conclusión contraria, indudablemente se encuentra habilitado para declarar lo contrario. Y ello es precisamente lo que ha acontecido en el caso de la especie». Sentencia de la Corte de Apelaciones de Santiago, rol 5310-2016, 3 de octubre de 2016, considerando 6, parte final.
}

18. Sentencia de la Corte Suprema, rol 100.759-2016, 29 de noviembre de 2018, considerando 18. 


\section{El desequilibrio importante}

En cuanto a este elemento, se ha señalado (De la Maza, 2012: 143) que no resulta susceptible de reducir a una fórmula general. Así, la verificación de un desequilibrio importante en los derechos y obligaciones que para las partes se derivan del contrato tiene un carácter eminentemente casuístico. De acuerdo con ello, el juez, dentro del marco que queda a su discreción, concretará este elemento exigido por la letra g) del artículo 16, según las circunstancias que rodeen al caso de que se trata.

Por otro lado, si bien la amplitud y vaguedad de la noción «desequilibrio importante» genera un gran margen para la discrecionalidad judicial (Llamas, 2004: 237), el artículo 16 letra g) provee al juez dos criterios para determinar ese desequilibrio en perjuicio del consumidor: la finalidad del contrato y las disposiciones especiales o generales que lo rigen.

La norma señala precisamente que el intérprete «atenderá» a estos dos criterios. $\mathrm{Al}$ respecto se ha sostenido que, si bien constituyen directrices que deben ser atendidas, no hay razón para estimar que son las únicas. En otras palabras, podría perfectamente el juez atender a otros criterios para constatar el desequilibrio (De la Maza, 2012: 143-145).

En relación con el concepto de desequilibrio, Corte Suprema ha sostenido:

Que concordante con lo anterior, conveniente resulta al tenor del precepto del artículo 16 letra g) de la ley citada, destacar que el concepto de desequilibrio que emplea el legislador, ha de entenderse como un «déficit jurídico» de manera que la abusividad no enfrenta lo que puede considerarse contenido económico del contrato, y por tanto no dice relación con las cláusulas de precio o de las condiciones económicas. En suma, lo relevante es la afectación a los derechos y obligaciones de los consumidores, ya sea que se altere el derecho dispositivo en contra del consumidor o, desde la perspectiva de éste, se fractura el propósito práctico del contrato. De tal forma entonces, la adhesión a un contenido contractual predispuesto por el proveedor viene garantizada por el amparo del mecanismo de protección sustantivo a partir de la idea de buena fe y equilibrio contractual.

En consecuencia, las señaladas cláusulas son abusivas por cuanto el carácter desproporcionado indica una situación inesperada y contraria a la normalidad de los contratos, no pudiendo ser aceptadas, atendida la confianza esperada por el consumidor. ${ }^{19}$

Asimismo, en el pronunciamiento de la Corte Suprema en el caso Sernac con $B B V A$, el tribunal establece unos criterios adicionales a las directrices legales señaladas en el artículo 16 letra g), a partir de los cuales es posible articular la fisonomía

19. Sentencia de la Corte de Apelaciones de Santiago, rol 8281-2013, 3 de junio de 2014, considerando noveno. 
que debe adoptar el examen de abusividad a la hora de constatar la existencia de un desequilibrio importante, de lo que se extraen las siguientes reglas: ${ }^{20}$

- Para determinar la existencia de un desequilibrio importante entre las prestaciones, se debe analizar la extensión de las prerrogativas que se confieren a una de las partes y a la posición en que, producto de dicha extensión, es puesto el adherente.

- La constatación de un desequilibrio importante «no requiere necesariamente la prueba de una situación de abuso real y concreto», pues basta la posibilidad de que la respectiva cláusula «valide una posición de abuso exorbitante con correlativo riesgo de detrimento y subordinación» del consumidor.

- Para constatar dicha posibilidad de abuso, se debe revisar el ámbito de acción que la cláusula cuestionada entrega a las partes «-que puede ser razonable y plausible atendidas las características de la relación-o, por el contrario, exorbitante y desmedido, generando el consiguiente riesgo de desmedro injusto de los derechos de la contraparte».

Sin perjuicio de ello, como se ha indicado, el artículo 16 letra g) provee al juez dos criterios para determinar si la cláusula en cuestión ha producido un desequilibrio importante en perjuicio del consumidor: la finalidad del contrato y las disposiciones especiales o generales que rigen el contrato. A continuación, se examinan ambos.

La finalidad del contrato. Con «la finalidad del contrato», el legislador parece referirse al «objetivo típico que un consumidor promedio busca satisfacer a través de la celebración del contrato y que el predisponente debe considerar al momento de celebrar el contrato» (De la Maza, 2012: 143-144). Se relaciona, además, esta finalidad con las «expectativas razonables del consumidor al momento de contratar». Esto quiere decir que el consumidor se hace una idea del contrato que está celebrando, y de los derechos y obligaciones que de éste derivan y, las cláusulas que modifiquen lo que «comúnmente se asocia a un tipo contractual deben estimarse como contrarias a las expectativas razonables del consumidor» (De la Maza, 2014: 345-346).

En este sentido, en un caso de interés individual, en que el consumidor había celebrado un contrato de tiempo compartido que contenía una cláusula en mérito, de la cual debía hacer un desembolso patrimonial por el no ejercicio de su derecho, y al haber cumplido el consumidor en tiempo y forma con el pago de su propia obligación, la Corte de Apelaciones de Santiago estableció que

Para determinar la finalidad del contrato, se ha entendido que se deben examinar las expectativas que el consumidor, razonablemente, podría haberse hecho respecto

20. Sentencia de la Corte Suprema, rol 100.759-2016, 29 de noviembre de 2018, considerando 17, parte final. 
del contrato, lo que implica que uno de los principales elementos para limitar el contenido abusivo de los contratos por adhesión, se encuentra en la noción de defraudación de expectativas del adherente. ${ }^{21}$

En la determinación del criterio relativo a la finalidad del contrato, se debe tener en cuenta, además, la relación con una regla de interpretación que, en el contexto de la contratación por adhesión, cobra especial relevancia. Se trata de la natural extensión del contrato (artículo 1.561 del Código Civil). De conformidad con esta regla, «no es posible extender los efectos de una declaración a circunstancias no previstas por las partes al momento de contratar», lo cual, en el caso de los contratos de adhesión, en que las estipulaciones consisten, normalmente, en cláusulas generales, implica que no es procedente «extender la usual generalidad de sus términos más allá de la materia particular sobre la que contrataron las partes» (Tapia y Valdivia, 199: 135).

Volvamos a las cláusulas sobre uso y tratamiento de datos personales. Si se examinan los fallos citados, a la luz de los anteriores comentarios, tanto en BBVA como en Ticketmaster, los tribunales destacan que la autorización para la recolección de información del usuario, y en especial su entrega a terceros, es excesiva si se toma en consideración el contexto contractual en el cual se ha - se presume- obtenido dicha autorización.

Así, en Sernac con BBVA, la Corte Suprema ha estimado que aquella cláusula en virtud de la cual se da atribución al predisponente (el banco) para entregar informaciones a toda clase de terceros - con quienes el consumidor no ha contratado- es «amplia o excesiva» o desequilibrada, de acuerdo con el tenor de la norma que se examina. Agrega la Corte que no existe justificación para una cláusula tal..$^{22} \mathrm{El} \mathrm{razo-}$ namiento del tribunal parece correcto, ya que es difícil sostener que el consumidor se represente de alguna forma la existencia de una cláusula como la cuestionada en un contrato bancario.

Por su parte, en Sernac con Ticketmaster, la Corte sostuvo, en lo pertinente que «en la medida en que la información recopilada no aparece delimitada, la autorización a revelar información a terceros aparece asimismo ilimitada». ${ }^{23}$ Luego, relacionando el asunto del contexto contractual con la infracción a la buena fe objetiva, agrega que

resulta contraria a la buena fe, y en consecuencia abusiva, la obtención del consentimiento del titular de los datos mediante una condición general de contratación incluida en una transacción cuyo objeto principal es la entrada a un espectáculo. En el contexto de semejante transacción comercial, tal renuncia a la privacidad de los datos personales solo es válida si es otorgada en forma explícita y específica.

21. Sentencia de la Corte de Apelaciones de Santiago, rol 3746-2007, 21 de septiembre de 2007, considerando 1.

22. Sentencia de la Corte Suprema, rol 100.759-2016, 29 de noviembre de 2018, considerando 36.

23. Sentencia de la Corte Suprema, rol 1533-2015, 7 de julio de 2016, considerando 11. 
La relevancia del examen del fin del contrato para la determinación si una cláusula de este tipo es abusiva o no, aparece también de manifiesto en el hecho de que, en ambos casos, la Corte Suprema las declaró nulas solo parcialmente, al estimar que existían hipótesis en que tales cláusulas podían considerarse válidas. Así, la Corte consideró - en ciertas circunstancias - ajustado a derecho el tratamiento de la información dentro de la esfera de la respectiva organización del proveedor.

En este sentido, en el caso BBVA la Corte señaló que

no puede ser atentatorio contra la buena fe ni lesiona el interés del cliente la circunstancia de que la información de que dispone el banco sobre el mismo como sujeto de crédito circule o se comparta entre las diversas unidades de la institución bancaria o personas relacionadas a ella, lo que incluso podrá beneficiarle. ${ }^{24}$

Por su parte, en el caso Ticketmaster, la Corte explica con claridad las circunstancias en que la obtención y uso de información por parte del proveedor es legítima:

La obtención de cierta información es ciertamente necesaria para generar las transacciones comerciales de venta de entradas. El operador del sitio necesita, al menos, la identidad del consumidor, la información relativa al medio de pago utilizado, e información para el despacho físico o virtual del comprobante de la transacción. Con tal objeto, el operador requerirá cierta información a objeto de proceder a la transacción. ${ }^{25}$

Las disposiciones generales o especiales que rigen el contrato. Se ha dicho que las disposiciones generales y especiales que rigen el contrato, a que hace referencia el artículo 16 letra g), consisten en las normas de derecho objetivo que disciplinan al contrato (De la Maza, 2012: 143).

En otras palabras, el intérprete debe tener en consideración las normas que resultan aplicables al contrato respectivo. En lo que a este trabajo interesa, tratándose de cláusulas sobre datos personales, las normas relevantes debiesen ser las de la Ley 19.628 sobre Protección de Datos Personales. En particular, es relevante lo dispuesto por el artículo 4, que dispone en su parte pertinente:

El tratamiento de los datos personales solo puede efectuarse cuando esta ley $\mathrm{u}$ otras disposiciones legales lo autoricen o el titular consienta expresamente en ello.

La persona que autoriza debe ser debidamente informada respecto del propósito del almacenamiento de sus datos personales y su posible comunicación al público.

La autorización debe constar por escrito.

Por ello resulta curioso que en los fallos del caso BBVA, ninguno de los tribunales

24. Sentencia de la Corte Suprema, rol 100.759-2016, 29 de noviembre de 2018, considerando 36.

25. Sentencia de la Corte Suprema, rol 1533-2015, 7 de julio de 2016, considerando 11. 
cite a la Ley 19.628, y que solo la Corte Suprema haga una críptica alusión a «la normativa de protección de datos reservados».

Por su parte, como se dijo, en Ticketmaster la Corte Suprema destaca que en virtud del artículo 4 de la Ley 19.628, la renuncia a la privacidad de los datos personales debe efectuarse de manera explícita y específica, por lo que es abusiva si se integra al contrato mediante una condición general de la contratación.

Ese último razonamiento no parece correcto. Como ya se indicó, si no hay autorización, simplemente habrá infracción al artículo 4, y la recolección y uso de los datos personales será ilícita por esa causa. Sin embargo, como también se dijo, lo que parece haber detrás del razonamiento de la Corte para declarar inválida la cláusula no es tan solo la falta de autorización del titular, sino que la concesión de facultades amplias - «ilimitadas», en palabras del tribunal- al proveedor para tales efectos, especialmente en lo relativo a la entrega de los datos a terceros.

De otra manera, no podría explicarse que los fallos estimen como válidas algunas de las hipótesis contenidas en las cláusulas respectivas. Ello solo es posible si se considera que el consumidor ha prestado un consentimiento válido y suficiente en los términos que exige el citado artículo 4. Si no fuere así - hay que insistir en esto-, el proveedor solo podría utilizar o tratar los datos personales del consumidor adherente en supuestos muy restringidos, expresamente autorizados por la misma Ley 19.628.

\section{La naturaleza onerosa o gratuita del contrato}

Por último, cabe referirse a una cuestión que puede ser determinante para establecer si una cláusula de esta naturaleza es abusiva o no. Se trata de dilucidar la naturaleza onerosa o gratuita del contrato celebrado entre proveedor y consumidor. ${ }^{26}$

En los dos casos a que se ha hecho referencia, se trataba de contratos a título oneroso, es decir, contratos en los cuales existía una contraprestación pecuniaria (en dinero) por parte del usuario a cambio del bien o servicio entregado por el proveedor.

Como se dijo, lo que parece abusivo en dichos casos es la pretensión del proveedor, mediante una autorización amplia y poco definida, de recolectar, usar y tratar datos personales del usuario más allá de los necesarios para la celebración o ejecución del contrato, o para fines completamente ajenos al mismo.

Sin embargo, la afirmación anterior pudiese ser cuestionada en el caso de contratos de naturaleza gratuita. En efecto, en el caso de un contrato oneroso, el usuario ha pagado por el bien o servicio, por lo que la autorización para que sus datos personales sean utilizados en provecho del proveedor puede ser desproporcionada, ya que significa un beneficio adicional - e injustificado- para este último.

26. Para una mirada a la valorización de los datos personales desde una perspectiva de libre competencia, véase Srinivasan (2019). 
Pero en el caso de los servicios que se prestan de manera gratuita, es decir, en que no se requiere una contraprestación dineraria por parte del usuario, la conclusión anterior merece ciertas precisiones. En un contrato gratuito, en el cual el usuario recibe algo a cambio de nada, la desproporción referida podría no existir o, al menos, no tener la entidad suficiente, sobre todo si el servicio que el usuario recibe de manera gratuita le presta una utilidad evidente, como sucede con el servicio de correo electrónico o de almacenamiento de datos. En otras palabras, pudiese considerarse razonable que el proveedor utilice los datos personales del usuario en su propio beneficio, fuera del ámbito o contexto contractual, ya que por su parte el usuario obtiene las ventajas del servicio respectivo.

La cuestión es relevante ya que, como es sabido, en un número importante de contratos celebrados en línea actualmente, todo o parte del contenido digital al que accede el usuario se le suministra sin una contraprestación en dinero. ${ }^{27}$ Así sucede, por ejemplo, en el caso de las redes sociales, streaming de video o música, y de servicios de correo electrónico o de almacenamiento de datos. ${ }^{28}$ Se trata, a primera vista, de contratos gratuitos: el usuario recibe la prestación de un servicio sin entregar nada a cambio, o en palabras del artículo 1.440 del Código Civil, es un contrato que tiene por objeto la utilidad de una de las partes (el usuario) sufriendo la otra el gravamen (el proveedor).

A la luz de la definición que entrega el Código Civil, la pregunta que surge de inmediato es por qué un proveedor - una empresa comercial que persigue obtener utilidades económicas- prestaría servicios tan esenciales como el de correo electrónico o de almacenamiento de datos de manera gratuita. La respuesta está dada por el modelo de negocios de este tipo de servicios. Este modelo se basa justamente en la recolección, tratamiento y comercialización de los datos personales de sus usuarios. Mediante lo que se ha denominado el negocio del big data, esto es, el tratamiento de enormes cantidades de información, se ha logrado dar un valor económico a los datos que voluntaria o involuntariamente proveen los usuarios al utilizar los servicios en línea, datos que son utilizados por los proveedores de bienes o servicios de contenido

27. Se utiliza el concepto de contenido digital que provee la Propuesta de Directiva del Parlamento Europeo y del Consejo relativa a determinados aspectos de los contratos de suministro de contenidos digitales (COM/2105/0634 final), la cual es su artículo 2.1 dispone: «A efectos de la presente directiva, se aplicarán las siguientes definiciones: i) "contenido digital": a) datos producidos y suministrados en formato digital, por ejemplo video, audio, aplicaciones, juegos digitales y otro tipo de software; b) servicio que permite la creación, el tratamiento o el almacenamiento de los datos en formato digital, cuando dichos datos sean facilitados por el consumidor, y c) servicio que permite compartir y cualquier otro tipo de interacción con datos en formato digital facilitados por otros usuarios del servicio». Disponible en http://bit.ly/2LJnjwR.

28. Ello sin perjuicio de ciertas modalidades especiales de dichos servicios, a las que el usuario solo puede acceder mediante el pago de una suma de dinero, como sucede por ejemplo con Dropbox. 
digital para ser empleados en beneficio de su propio negocio o para comercializados a terceros (Friedman, 2008; Helberger, 2016). El tratamiento de los datos personales permite a los proveedores elaborar perfiles de sus usuarios, de manera de ofrecer un marketing personalizado, por el cual los anunciantes están dispuestos a pagar más. Por otra parte, también les permite mejorar de manera continua sus modelos analíticos y predictivos, de modo de aplicarlos a futuros usuarios, lo que aumenta el valor intrínseco del negocio o empresa (Grundmann y Hacker, 2018: 41).

Por ello, se ha sostenido que si el usuario autoriza la recolección, tratamiento y comercialización de sus datos personales al proveedor de contenidos digitales, la gratuidad de tales servicios es solo aparente (De Franceschi y Lehmann, 2014; Langhanke y Schmidt-Kessel, 2015). En este caso, el usuario está también entregando algo con valor económico al proveedor, es decir, existe una contraprestación pecuniaria, que no está constituida por el pago de un precio en dinero, sino por el acceso a los datos personales que el usuario genera. Se trataría, entonces, de un contrato oneroso, ya que existe un intercambio económico, o en los términos del artículo 1.440 del Código Civil, un contrato que tiene por objeto la utilidad de ambos contratantes, gravándose cada uno a beneficio del otro.

Si esta interpretación es correcta, tanto un contrato en que el usuario pagase por el bien o por la prestación del servicio, como uno en que tal bien o servicio se entregase o prestase sin contraprestación dineraria - pero a cambio de la autorización para el uso y tratamiento de datos personales-, debiesen evaluarse de igual manera respecto al carácter abusivo o no de tales cláusulas. En ambos casos, entonces, podría ser desproporcionado y contrario a la buena fe, que el proveedor utilizase los datos del usuario para fines ajenos al contexto contractual, ya que ello le otorgaría un beneficio excesivo o incluso injustificado.

Un segundo aspecto, no menos relevante de considerar como oneroso o gratuito al contrato, es que tal definición determinará en el derecho chileno el régimen legal aplicable: el del derecho común o el de protección a los consumidores. ${ }^{29}$ Solo si se entiende que el contrato queda regido por esta última ley, podrá examinarse lo abusivo o no de sus cláusulas.

Hay que recordar que el artículo 1 número 1 de la Ley 19.496 exige, para que ésta sea aplicable, que el consumidor, en virtud de cualquier acto jurídico oneroso, adquiera, utilice o disfrute, como destinatario final, un bien o servicio. Hasta ahí, no parece haber objeción, ya que si bien la valorización pecuniaria de la autorización para el tratamiento de datos personales pueda ser difícil, sí puede estimarse que da lugar a una relación onerosa entre consumidor y proveedor. Sin embargo, las dificultades comienzan cuando se examina lo prescrito en el número 2 de la misma norma, que exige, para que la otra parte se considere proveedor, que éste cobre un precio o

29. Sobre el ámbito de aplicación de dicha normativa, véase Momberg Uribe (2013a). 
tarifa por el bien o servicio. Lo cierto es que es problemático considerar a la tantas veces mencionada autorización como un precio, por lo que podría objetarse que en los casos en que no se cobre una suma de dinero, se configure una relación de consumo, y, por lo tanto, no cabría aplicar la Ley 19.496. Siguiendo esta interpretación, la relación del usuario con Facebook, Twitter y Gmail, entre otros, sería simplemente una de carácter civil.

La cuestión es discutible, ya que el concepto de precio en nuestro ordenamiento está asociado al pago de una suma de dinero (artículo 1.793 del Código Civil), y no a la entrega o transferencia de algún otro bien. A ello deben sumarse las dificultades para determinar el valor económico de los datos de un usuario individual. Sin embargo, tampoco debe olvidarse que la Ley de Protección del Consumidor es una ley especial, en la que no necesariamente se siguen las definiciones legales de manera estricta, como sucede, por ejemplo, con la definición de oferta que contiene el artículo 1 numeral 8. A ello se puede agregar que no todos los contratos de consumo son compraventas y, por lo mismo, el concepto de precio en contratos de naturaleza diversa pudiese ser distinto al del artículo 1.793. Por último, debe recordarse que la noción de acto jurídico oneroso del artículo 1 numeral 1 de la Ley, que determina quién es consumidor, ha sido interpretada de manera amplia por la doctrina y los tribunales (Momberg Uribe, 2013a: 6).

\section{Conclusiones}

En el presente trabajo se ha pretendido demostrar que una cláusula sobre uso y tratamiento de datos personales podría ser considerada abusiva, sobre la base del artículo 16 letra g) de la Ley 19.496, aun cuando se entienda que se ha prestado el consentimiento a que se refiere el artículo 4 de la Ley 19.698.

Como se ha explicado, ello sucederá si la cláusula en cuestión es una que presumiblemente el consumidor no habría aceptado en un contrato negociado de manera libre; y que tampoco podía en forma razonable esperar que se incluyera tomando en cuenta el objeto del contrato, lo cual se puede entender como una transgresión a la buena fe objetiva a que alude el artículo 16 letra g). Por su parte, el desequilibrio importante a que se refiere la misma norma, se presentará cuando la autorización para la recolección de información del usuario y en especial su entrega a terceros sea excesiva, considerando de nuevo el contexto contractual en el cual, se presume, se ha obtenido dicha autorización.

Por último, no debiese influir en la determinación del carácter abusivo o no de una cláusula de esta especie, el carácter oneroso o gratuito del contrato, si se acepta la tesis de que si el usuario autoriza la recolección, tratamiento y comercialización de sus datos personales al proveedor de contenidos digitales, la gratuidad de tales servicios es solo aparente, ya que el usuario estaría entregando algo con valor económico 
al proveedor, es decir, existe una contraprestación pecuniaria, que no está constituida por el pago de un precio en dinero, sino por el acceso a los datos personales que el usuario genera.

\section{Agradecimientos}

Este trabajo se enmarca dentro del proyecto Fondecyt Iniciación núm. 11190543.

\section{Referencias}

Boestsch, Cristián (2015). La buena fe contractual. Santiago: Ediciones UC.

Contreras Vásquez, Pablo y Pablo Trigo Kramcsák (2019). «Interés legítimo y tratamiento de datos personales: Antecedentes comparados y regulación en Chile». Revista Chilena de Derecho y Tecnología, 3 (1): 69-106. DOI: 10.5354/0719-2584.2019.52915.

De Franceschi, Alberto y Michael Lehmann (2014). «Data as tradeable commodity and new measures for their protection». The Italian Law Journal, 1 (1): 51-72. Disponible en http://bit.ly/2rpUSgz.

De la MAZA, Íñigo (2012). «El control de las cláusulas abusivas y la letra g)». En Francia Barrientos, Íñigo de la Maza y Carlos Pizarro, Consumidores, Santiago: Thomson Reuters.

-. (2014). «¿Pero qué es lo que esperabas? Contratos por adhesión y expectativas razonables». En Susan Turner y Juan Andrés Varas (coordinadores), Estudios de derecho civil 9. Santiago: Thomson Reuters.

De la MazA, Î́nigo y Rodrigo Momberg Uribe (2017). «Términos y condiciones: Acerca del supuesto carácter contractual de las autorizaciones para el tratamiento de datos personales en sitios web». Revista Chilena de Derecho y Tecnología, 6 (2): 25-55. DOI: 10.5354/0719-2584.2017.46226.

-. (2018). «La transparencia como mecanismo de tutela de la privacidad de los consumidores y usuarios en contratos electrónicos». Revista Chilena de Derecho y Tecnología, 7 (2): 81-111. DOI: doi.org/10.5354/0719-2584.2018.48812.

DíEz-PiCAzo, Luis (1993). Fundamentos del derecho civil patrimonial. Madrid: Civitas. Eyzaguirre, Cristóbal y Javier Rodríguez (2013). «Expansión y límites de la buena fe objetiva: A propósito del proyecto de principios latinoamericanos de derecho de los contratos». Revista Chilena de Derecho Privado, (21): 137-216. DOI: 10.4067/ So718-80722013000200005.

Friedman, David (2008). «Free offers: A new look». New Mexico Law Review, 38 (1): 49-94. Disponible en https://bit.ly/2LEwYEM.

Frigerio, Catalina (2018). «Mecanismos de regulación de datos personales: Una mirada desde el análisis económico del derecho». Revista Chilena de Derecho y Tecnología, 7 (2): 45-80. DOI: 10.5354/0719-2584.2018.50578. 
Grundmann, Stefan y Philipp Hacker (2018). «The digital dimension as a challenge to European Contract Law: The architecture». En Stefan Grundmann (editor), European Contract Law in the digital age. Cambridge: Intersentia.

Helberger, Natali (2016). "Profiling and targeting consumers in the internet of things: New challenge for Consumer Law». En Reiner Schulze y Nick Staudenmayer (editores), Digital revolution: Challenges for Contract Law in practice. BadenBaden: Nomos.

Langhanke, Carmen y Martin Schmidt-Kessel (2015). «Consumer data as consideration». Journal of European Consumer and Market Law, 6: 218-223. Disponible en https://bit.ly/2PvUWTX.

Llamas, Eugenio (2004). «Buena fe y cláusulas abusivas en la contratación con consumidores». En Marcos Córdova (director), Tratado de la buena fe en el derecho. Buenos Aires: La Ley.

Momberg Uribe, Rodrigo (2013a). «Comentario al artículo 1 número 1: Definición consumidores o usuarios». En Íñigo de la Maza y Carlos Pizarro (directores), La protección de los derechos de los consumidores. Santiago: Thomson Reuters.

-. (2013b). «El control de las cláusulas abusivas como instrumento de intervención judicial en el contrato». Revista de Derecho (Valdivia), 26 (1): 9-27. DOI: 10.4067/ So718-09502013000100001.

-. (2017). «Acciones colectivas y Ley 19.628 sobre protección de la vida privada y datos de carácter personal». Revista Chilena de Derecho Privado, 28: 357-363.

-. (2019). «La contraprestación del usuario en los contratos sobre contenido digital». En Susan Turner y Juan Andrés Varas (directores), Estudios de derecho civil 9. Santiago: Thomson Reuters.

Momberg Uribe, Rodrigo y Carlos Pizarro (2013). «Comentario al artículo 16 letra g)». En Íñigo de la Maza y Carlos Pizarro (directores), La protección de los derechos de los consumidores. Santiago: Thomson Reuters.

Morales, María Elisa (2019). «Algunas notas sobre la noción de cláusula abusiva». En Carlos Céspedes (editor), Estudios de derecho privado en memoria del profesor Nelson Vera Moraga. Santiago: Thomson Reuters.

Polo, Eduardo (1990). Protección del contratante débil y condiciones generales de los contratos. Madrid: Civitas.

SRINIVASAN, Dina (2016). «The antitrust case against Facebook: A monopolist's journey towards pervasive surveillance in spite of consumers' preference for privacy». Berkeley Business Law Journal, 16: 39-101. Disponible en https://bit.ly/2P86PjK.

Summers, Robert (1968). "Good faith" in general Contract Law and the sales provisions of the Uniform Commercial Code». Virginia Law Review, 54 (2): 195-267. Disponible en http://bit.ly/2PwnDQB.

TAPIA, Mauricio y José Miguel Valdivia (1999). Contrato por adhesión: Ley 19.496. Santiago: Jurídica de Chile. 


\section{Sobre los autores}

Rodrigo Momberg Uribe es abogado. PhD de la Universidad de Utrecht, Países Bajos. Profesor de Derecho Civil de la Pontificia Universidad Católica de Valparaíso, Chile. Su correo electrónico es rodrigo.momberg@pucv.cl. (D) http://orcid. org/0000-0002-4774-4256.

María Elisa Morales Ortiz es abogada. Licenciada en Ciencias Jurídicas y Sociales por la Universidad Austral de Chile. Doctora en Derecho por la Universidad de Chile. Académica del Departamento de Ciencias Jurídicas de la Facultad de Ciencias Jurídicas y Empresariales de la Universidad de La Frontera. Su correo electrónico es elisa.moralesortiz@gmail.com. (D) http://orcid.org/0ooo-0003-1200-7253. 


\title{
REVISTA CHILENA DE DERECHO Y TECNOLOGÍA
}

La Revista de Chilena de Derecho y Tecnología es una publicación académica semestral del Centro de Estudios en Derecho Informático de la Facultad de Derecho de la Universidad de Chile, que tiene por objeto difundir en la comunidad jurídica los elementos necesarios para analizar y comprender los alcances y efectos que el desarrollo tecnológico y cultural han producido en la sociedad, especialmente su impacto en la ciencia jurídica.

\author{
EDITOR GENERAL \\ Daniel Álvarez Valenzuela \\ (dalvarez@derecho.uchile.cl) \\ SITIO WEB \\ rchdt.uchile.cl \\ CORREO ELECTRÓNICO \\ rchdt@derecho.uchile.cl \\ LICENCIA DE ESTE ARTÍ́CULO \\ Creative Commons Atribución Compartir Igual 4.o Internacional
}

\begin{abstract}
La edición de textos, el diseño editorial
y la conversión a formatos electrónicos de este artículo

estuvieron a cargo de Tipográfica

(www.tipografica.cl).
\end{abstract}

